\title{
Tropical pancreatitis
}

INSERM

\section{Source}

INSERM. (1999). Orphanet: an online rare disease and orphan drug data base. Tropical pancreatitis. ORPHA:103918

Tropical pancreatitis is a rare pancreatic disease of juvenile onset occurring mainly in tropical developing countries and characterized by chronic non-alcoholic pancreatitis manifesting with abdominal pain, steatorrhea and fibrocalculous pancreatopathy (see this term). It is also commonly associated with the development of pancreatic calculi and pancreatic cancer at a much higher frequency than seen in ordinary chronic pancreatitis. 